\title{
High Throughput Mass Spectrometry Platform for Prospecting High Value Chemicals from Bioconversion of Glycerin
}

\author{
Diana R. Amazonas, ${ }^{\circledR a}$ Augusto L. Souto, ${ }^{a}$ Flávia S. Vieira, ${ }^{a, b}$ Andréia A. J. Carneiro, ${ }^{a}$ \\ Rebeca B. Vianna, ${ }^{a}$ Thaís D. Mendes, ${ }^{a}$ Karen S. Lima, ${ }^{a}$ José A. A. Ribeiro, ${ }^{a}$ \\ Mônica C. T. Damaso, ${ }^{a}$ Clenilson M. Rodrigues ${ }^{a}$ and Patrícia V. Abdelnur ${ }^{\circledR *, a, b}$ \\ ${ }^{a}$ Empresa Brasileira de Pesquisa Agropecuária, Embrapa Agroenergia, W3 Norte, PqEB, Asa Norte, \\ 70770-901 Brasília-DF, Brazil \\ ${ }^{b}$ Instituto de Química, Universidade Federal de Goiás, Campus Samambaia, \\ 74690-900 Goiânia-GO, Brazil
}

\begin{abstract}
The use of bioprocess to convert low valued biomass or agroindustrial byproducts into high-value chemicals is an emerging area. However, laboratories usually use outdated analytical techniques to identify bioproducts, losing valuable information, such as the identification of unexpected compounds. In this work, we presented a successful systematic and modern analytical approach based on direct infusion mass spectrometry (DIMS) for an automated high-throughput screening of untargeted compounds from glycerin bioconversion process. We describe advantages of DIMS and its combined application with chemometrics towards an untargeted metabolomics approach to analyze several samples in a short time (11 samples per $\mathrm{h}$ ). Three batches with 34 samples from the bioconversion of glycerin using several filamentous fungi strains were analyzed. Batch 347 was selected as promising, since high value chemicals, such as amide, phenolic and acid compounds, were identified. The platform presented was fast, robust, and versatile, then it could be applied to different bioprocesses.
\end{abstract}

Keywords: metabolomics, mass spectrometry, DIMS, biotechnology, filamentous fungi

\section{Introduction}

Biotechnology is an expanding area worldwide, with a great potential to increase in the next years. Industries, from fragrance to chemicals, are adopting bioprocess, mostly because of the high selectivity of the reactions, which results in a production of specific compounds. Another successful application of biotechnology is the production of chemicals from byproducts or residues from different agroindustrial chains, resulting in an economic growth and reduction of environmental impacts for the industry, which are directly related to circle economy and biorefinery concepts. ${ }^{1,2}$

Glycerin is a byproduct of biodiesel production with low commercial value, being burnt or sold as cheap raw material for the industry. ${ }^{3}$ For each $90 \mathrm{~m}^{3}$ of biodiesel produced by transesterification, approximately $10 \mathrm{~m}^{3}$ of glycerin is generated. ${ }^{4}$ In 2008 , the Brazilian National Agency of Petroleum, Natural Gas and Biofuels

\footnotetext{
*e-mail: patricia.abdelnur@embrapa.br
}

established as mandatory to mix $2 \%$ of biodiesel with diesel of fossil origin, and since then, this percentage has been increasing. ${ }^{5}$ Recently, with the publication of Resolution No. 16 of CNPE (National Energy Policy Council), ${ }^{6}$ there was an increase in the mix to $10 \%$, mandatorily reaching at least $11 \%$ in September 2019. So, the conversion of glycerin into new chemicals has been investigated by different groups to add value to this byproduct. Although bioconversion of glycerin is a promising area, the discovery of powerful microorganism as well as the bioprocess parameters optimization to produce considerable amount of chemicals from glycerin is a difficult task. ${ }^{7-9}$ In this scenario, high-throughput analysis is crucial to provide a fast screening of potential microorganisms in a large biological collection. ${ }^{10}$

The development of a product in biotechnology is performed using biological systems, living organisms or derivatives, and different metabolic pathways could be involved in the bioprocess. ${ }^{11}$ But the production of an interest chemical from a byproduct using biotechnology is not trivial. ${ }^{8,12,13}$ There are mainly two approaches: $(i)$ the 
screening of powerful microorganism; or (ii) the microbial genetic breeding. The last strategy is used to produce a specific and "targeted" compound, where metabolic pathways are well-known in the bioprocess. ${ }^{12,14}$

Screening of powerful microorganism has been widely used to bioprospecting new chemicals from industrial byproducts or residues. ${ }^{15,16}$ However, a bottleneck is the identification of unknown chemical compounds or metabolites produced by the bioprocess, since several classes of compounds, with different chemical structure, could be easily produced by microorganisms. ${ }^{17}$ The end products may be related to different metabolic pathways and are not been easily predictable..$^{12,14}$

Usually, low sensitive and non-selective analytical techniques, such as high performance liquid chromatography coupled to photodiode array detector (HPLC-PDA), are used to separate and identify the compounds generated in the bioprocess. ${ }^{18,19}$ However, this analysis is time consuming and restricted to the identification of products according to commercial available standards, losing the identification of several compounds. ${ }^{19}$

High resolution mass spectrometry (HRMS) is a powerful analytical technique that enables compound identification (ID), not always requiring commercial standards. ${ }^{20}$ New MS instruments are able to provide a compound ID in a molecular formula with good accuracy, according to their $\mathrm{m} / \mathrm{z}$ (mass per charge) ratio and isotope patterns, and, after libraries comparison as ChEBI, ${ }^{21}$ KEGG $^{22}$ and METLIN. ${ }^{23}$

Direct infusion mass spectrometry (DIMS) is a fast and practical analytical technique, not requiring any prior separation step, and resulting in high-throughput analysis (less than 1 min per sample). Although the use of DIMS and HRMS is a great strategy to perform compounds identification in a fast way, it is not suitable for a large number of samples, since sample injection and intersample cleaning is done manually, resulting in a poor reproducibility, cross contamination, and long time of cleaning inter-samples.

Automated DIMS has become very useful as a high-throughput metabolite fingerprinting or compound screening tool. However, some drawbacks of DIMS are the ion suppression effect and no discrimination of isobaric or isomer compounds, ${ }^{24}$ because to increase speed of analysis and simplify the acquisition of data, the removal of the analytical column is the main strategy in DIMS. ${ }^{25}$ But DIMS has important advantages, in other words, it requires minimum sample pre-treatments, no chromatographic separation and its instrument cycle is around $5 \mathrm{~min}$, which enables the analysis of more than 1,000 samples per week without significant problems in data quality. An automated DIMS takes the advantage of modern autosamplers, where the column compartment is bypassed allowing direct injection into the ion source, such as electrospray ionization (ESI). ${ }^{26}$ Therefore, it can be an excellent tool for "first-pass" metabolome analysis or compound fingerprinting of complex biological samples. ${ }^{27}$

DIMS has been applied as useful metabolomics tool to distinguish ecotypes, cultivars and plant varieties by the identification of specific metabolites. ${ }^{28,29}$ However, in biotechnology, this method is not common. In our knowledge, there is no published work using automated DIMS in an untargeted approach to bioprospecting chemicals using bioprocesses with filamentous fungi strains. Usually, to investigate the production of value-added compounds from microorganisms in bioprocesses other techniques are applied. ${ }^{30}$ On the other hand, these studies involving microorganisms and bioprocesses are restricted to targeted metabolomics approach, investigating specific metabolic pathways. ${ }^{31}$

In general, untargeted mass spectrometry approach provides a large amount of data, and data interpretation is not simple, then, the integration of DIMS and multivariate data analysis such as principal component analysis ${ }^{32}$ (PCA) could be used to selected potential microorganisms capable to produce interesting compounds by bioconversion. So, in the present work, the compounds were identified by comparison with databases after DIMS integrated with PCA analysis. Finally, interest chemicals were found in the screening as well as potential bioprocess conditions able to convert glycerin in a new biotechnology application.

In this context, we have proposed an automated high throughput analytical method to detect and identify a broad range of compounds, even the unexpected ones, produced by the microorganisms, after glycerin bioconversion, in a fast and versatile way.

\section{Experimental}

\section{Chemicals}

For the inoculum culture medium, potato dextrose agar (PDA) was purchased from Kasvi (Roseto degli Abruzzi, Italy) and yeast nitrogen base (YNB) from Sigma (St. Louis, MO, USA). For the glycerin bioconversion, $\left(\mathrm{NH}_{4}\right)_{2} \mathrm{SO}_{4}$ was purchased from Synth (Diadema, SP, Brazil) and palm ash was kindly donated by Military Institute of Engineering (Rio de Janeiro, RJ, Brazil). Crude glycerin (52 wt.\% glycerol purity) from commercial soybean biodiesel production was kindly donated by the Brazilian biodiesel plant from Cesbra Química S/A, Volta Redonda, RJ, Brazil. 
For DIMS experiments, liquid chromatography (LC)-MS-grade acetonitrile and methanol were purchased from Merck (Billerica, MA, USA); formic acid was purchased from Sigma-Aldrich (São Paulo, Brazil); and ultrapure water $(\geq 18 \mathrm{M} \Omega \mathrm{cm}$ ) was obtained from a Millipore Milli-Q purification system (Bedford, MA, USA).

For ultra-high performance liquid chromatography coupled to photodiode array detector (UHPLC-PDA) experiments, citric acid and anhydrous monobasic potassium phosphate were purchased from Sigma-Aldrich (São Paulo, Brazil); HPLC-grade methanol was purchased from J.T. Baker (Xelostoc, Mexico State, Mexico); phosphoric acid $85 \%$ was purchased from Panreac (Barcelone, Catalonia, Spain); and ultrapure water $(\geq 18 \mathrm{M} \Omega \mathrm{cm})$ was obtained from a Millipore Milli-Q purification system (Bedford, MA, USA).

\section{Biological samples}

Regarding microorganisms, we used 34 previously isolated filamentous fungi to test the crude glycerin bioconversion. Strains from batch 347 (samples 1 to 11) were isolated from different sources: soil and leaves of palm planting, Elaeis guineensis (1 to 5 and 8); strains 6 and 7 were isolated, respectively, from palm oil and palm fiber, and strains 9 to 11 were isolated from Jatropha curcas cake. Strains from batch 461 (samples 12 to 21) were isolated from leaves and roots of sugarcane plants (Saccharum officinarum). Strains from batch 430 (samples 22 to 34) were isolated from Sucupira's farm soil (Brasília, DF, Brazil) enriched with glycerin for 2 months. All strains are maintained in the Collection of Microorganisms and microalgae applied to agroenergy and biorefinery from Embrapa Agroenergy, Brasília, DF, Brazil. They are preserved by the Castellani method ${ }^{33}$ and by freezing using glycerol $\left(-80^{\circ} \mathrm{C}\right)$ and have not yet been identified.

\section{Crude glycerin bioconversion}

Pure filamentous fungi were reactivated in a potato dextrose agar medium. Pre-cultures for glycerin bioconversion experiments were grown in an agar YNB medium using only crude glycerin $\left(40 \mathrm{~g} \mathrm{~L}^{-1}\right)$ as the carbon source with the purpose of their adaptation. The bioconversion experiments were carried out in $250 \mathrm{~mL}$ cell culture flasks containing $50 \mathrm{~mL}$ of medium with the following composition: $0.5 \mathrm{~g} \mathrm{~L}^{-1}$ ammonium sulfate, $0.2 \mathrm{~g} \mathrm{~L}^{-1}$ palm ash and approximately $30 \mathrm{~g} \mathrm{~L}^{-1}$ of crude soybean glycerin. The medium's $\mathrm{pH}$ was adjusted to 6.0 and then sterilized $\left(121^{\circ} \mathrm{C}, 20 \mathrm{~min}\right)$. The bioconversion medium was inoculated with 4 disks $(0.8 \mathrm{~cm}$ diameter) or a spore suspension of $10^{7}$ spores $\mathrm{mL}^{-1}$ containing filamentous fungi previously grown in the pre-culture medium. All cultures were cultivated in triplicate in a batch fermentation process using an orbital shaker at $120 \mathrm{rpm}$ and $28^{\circ} \mathrm{C}$. A blank of fermentation was carried out under identical operating conditions, except for the absence of inoculum. Aliquots of the experiments and controls were collected on the $10^{\text {th }}$ day of cultivation, centrifuged for $10 \mathrm{~min}$ at $10,600 \times \mathrm{g}$ and the supernatant stored at $-20^{\circ} \mathrm{C}$.

\section{Analytical techniques}

Automated DIMS experiments were performed using an ultra-high performance liquid chromatograph (Nexera $\mathrm{X} 2$, Shimadzu, Japan) coupled to a high resolution mass spectrometer (maXis 4G UHR-TOF, Bruker Daltonics, Germany), with an ESI source in the positive [ESI(+)-MS] and in the negative ion mode [ESI(-)-MS]. DIMS were performed using methanol: $\mathrm{H}_{2} \mathrm{O}(1: 1, \mathrm{v}: \mathrm{v})$ as the carrier solvent. The analysis time was 5.4 min per sample at a variable flow rate as followed: $0.01 \mathrm{~mL} \mathrm{~min}^{-1}$ from 0-3 min, $0.4 \mathrm{~mL} \mathrm{~min}^{-1}$ from 3.01-5 min (flush-cleanup step), and $0.01 \mathrm{~mL} \mathrm{~min}{ }^{-1}$ from 5.01-5.4 min. Mass spectrometer parameters used for both ion polarities were as follows: end plate offset (+/-), $500 \mathrm{~V}$; capillary voltage (+/-), $4000 \mathrm{~V}$; nebulizer pressure, 4 bar; drying gas (nitrogen) flow rate, $5 \mathrm{~L} \mathrm{~min}^{-1}$; drying gas temperature, $180{ }^{\circ} \mathrm{C}$; acquisition spectra rate, $1 \mathrm{~Hz}$; monitoring a mass range from $\mathrm{m} / \mathrm{z}, 70$ to 1000 . Sodium formate solution $(10 \mathrm{mM} \mathrm{NaOH}$ solution in $1: 1 \mathrm{v}: \mathrm{v}$ isopropanol:water containing $0.2 \%$ formic acid) was directly injected through a 6-port valve before each MS injection to MS calibration.

Biological samples were diluted 1000 times in a $2 \mathrm{~mL}$ vial, with a solution of methanol: $\mathrm{H}_{2} \mathrm{O}(1: 1, \mathrm{v}: \mathrm{v})$, and then homogenized at vortex for $1 \mathrm{~min}$. Volume of injection in the chromatographic system was $4 \mu \mathrm{L}$ using UHPLC autosampler with technical duplicate. Tandem mass spectrometry (MS/MS) parameters were set in order to improve mass fragmentation in both ion polarity, positive and negative, with collision energy varying from 20 to $50 \mathrm{eV}$, using a stepping method. Precursor ions were acquired using cycle time of $3.0 \mathrm{~s}$. General AutoMS settings were: mass range, $\mathrm{m} / \mathrm{z} 70$ to 1000 ; spectra rate, $1 \mathrm{~Hz}$; pre pulse storage, $8 \mu \mathrm{s}$; funnel 1 radio frequency (RF), 150.0 volts peak-to-peak (Vpp).

All data was acquired by HyStar Application version 3.2 (Bruker Daltonics, Germany). DataAnalysis 4.2 (Bruker Daltonics, Germany) was used for data processing. The elucidation of the molecular formula of ions was done using SmartFormula algorithm and compound identification was performed using CompoundCrawler that allowed searches 
in $\mathrm{KEGG}^{22}$ and $\mathrm{ChEBI}^{21}$ databases. Further we used METLIN $^{23}$ database to characterize MS data as well as to fragmentation profiles investigation to identify molecules.

UHPLC-PDA experiments were carried out on an ultra-high performance liquid chromatography system (Acquity H-Class, Waters, Milford, MA, USA) coupled to a photodiode array detector (PDA), equipped with a quaternary solvent manager (QSM), an Acquity (USA) sample manager (SM), a column heater, a degassing system controlled by Empower PRO software version 3. Chromatographic separation was performed on an HSS T3 column $(150 \times 2.1 \mathrm{~mm}, 1.8 \mu \mathrm{m}$, Waters Acquity UPLC, USA) equipped with its respective pre-column. The mobile phase consisted of A (buffer solution of $0.01 \mathrm{M} \mathrm{KH}_{2} \mathrm{PO} 4$ at $\mathrm{pH} 2.0$ ) and $\mathrm{B}$ (methanol) performed with gradient elution. The buffer solution was prepared by dissolving $1.36 \mathrm{~g}$ of $\mathrm{KH}_{2} \mathrm{PO}_{4}$, weighed in UX620H semi-analytical balance (Shimadzu ${ }^{\circledR}$, Japan), in $1 \mathrm{~L}$ of ultra-pure water (Milli-Q, USA). The $\mathrm{pH}$ was adjusted with phosphoric acid, and the pre-calibrated $\mathrm{pH}$ meter model $827 \mathrm{pH}$ lab (Methohm®, Switzerland) was used to check the $\mathrm{pH}$ of the solution. After preparation, the buffer solution was sonicated for 15 min for complete dissolution of the reagents. The flow rate was $0.3 \mathrm{~mL} \mathrm{~min}^{-1}$ and the injection volume was $1 \mu \mathrm{L}$. Column temperature was maintained at $30^{\circ} \mathrm{C}$ and detection wavelength was settled on $210 \mathrm{~nm}$. Elution was performed as isocratic from 0 to $1.5 \mathrm{~min}(100 \% \mathrm{~A})$, linear gradient from 1.5 to $5 \mathrm{~min}(100-95 \% \mathrm{~A})$, linear gradient from 5 to $8 \min (95-85 \% \mathrm{~A})$, isocratic from 8 to $9(85 \% \mathrm{~A})$ and isocratic from 9 to $14 \min (100 \% \mathrm{~A})$ to equilibrate the column before next injection. For quantification we used commercial standard of citric acid with dilutions in water for calibration curve construction $(0.04,0.08,0.15,0.38$, $0.75,1.5,3,4.5$ and $\left.6 \mathrm{mg} \mathrm{mL}^{-1}\right)$. The limits of detection (LOD) and quantification (LOQ) were established based on the signal/noise ratio of $3: 1$ and $10: 1$, respectively. ${ }^{34}$ Successive dilutions of the standard solution were performed until concentration values were obtained with signal ratio $\geq 3$ for LOD and $\geq 10$ for LOQ.

\section{Chemometric analysis}

MS spectra data pre-processing was performed with Profile Analysis software (version 2.1, Bruker Daltonics, Germany), which were normalized by the largest bucket value and reduced into an ASCII file, containing a data matrix of the 34 samples versus integral segments (9302 at positive ionization mode and 9269 at negative ionization mode). PCA was performed using the Unscrumbler X software. ${ }^{35}$ Prior to PCA analysis, all data variables were normalized by area and scaled by mean centering. The PCA validation was performed using cross validation method random with 20 segments and 5 samples per segment.

\section{Results and Discussion}

Microorganisms (fungi) were isolated from different places to increase the heterogeneity. This strategy is used to increase the diversity of the strains to be evaluated and the variety of compounds produced. The chemicals portfolio produced from the bioconversion of glycerin was focused into the targets: organic acids, polyols and diols, that can be used in different industrial sectors, such as cosmetic, pharmaceutical and food industry.

Three batches of glycerin bioconversion samples (347, 461 and 430) were analyzed. In each batch, different microorganisms were cultivated, with 11 microorganisms in 347 (samples 1 to 11), 10 microorganisms in 461 (samples 12 to 21 ) and 13 microorganisms in 430 (samples 22 to 34 ), all of them prepared in biological triplicate (A, B, C) and technical duplicate injection (1 and 2). Thus, the code of samples is $1 \mathrm{~A} 1,1 \mathrm{~A} 2,1 \mathrm{~B} 1,1 \mathrm{~B} 2,1 \mathrm{C} 1,1 \mathrm{C} 2,2 \mathrm{~A} 1,2 \mathrm{~A} 2$, $2 \mathrm{~B} 1$, etc. following the increasing order.

The bioprocessed samples were analyzed by DIMS in a positive and negative electrospray ionization modes: ESI(+)-MS and ESI(-)-MS. A bucket table with all samples was generated in Profile Analysis software (Bruker Daltonics), using as delta of time analysis $78 \mathrm{~s}$ and as delta of the ratio $\mathrm{m} / \mathrm{z} 0.1$, with a range $(\mathrm{m} / \mathrm{z}$ ) of 70 to $1000 \mathrm{ppm}$. Then PCA plots and bar plots were generated using Unscrambler X software ${ }^{34}$ to do a screening of samples with interesting compounds. The validation results from PCA analysis are presented in Supplementary Information (SI, Table S1 and Figure S1).

The first PCA shows the scores plot from ESI(+)MS data (Figure 1), which resulted in three clusters corresponding to each batch of samples: 347 (in blue), 430 (in red) and 461 (in green). Scores plot distribution of 430 and 461 were more homogenous with greater similarity comparing to 347 , which showed a higher dispersion of their samples. This PCA result is very consistent, with an explained variance of $92 \%$, with $79 \%$ for principal component 1 (PC-1) and $13 \%$ for PC-2.

The most important ions highlighted in the scores plot (Figure 1) using ESI(+)-MS data are presented in the loadings plot (Figure 2). According to the Figure 2, the ions that most influenced the separation between the groups were $m / z 115.05$ (found mass $[\mathrm{M}+\mathrm{Na}]^{+} \mathrm{m} / z 115.0366$ ) and $\mathrm{m} / \mathrm{z} 304.25$ (found mass $[\mathrm{M}+\mathrm{Na}]^{+} \mathrm{m} / \mathrm{z}$ 304.2623). After comparison with KEGG and METLIN database platforms and literature search, the ion $[\mathrm{M}+\mathrm{Na}]^{+} \mathrm{m} / z 115.0366$ were assigned to the glycerol/glycerin $\left(\mathrm{C}_{3} \mathrm{H}_{8} \mathrm{O}_{3}\right)$, and the 


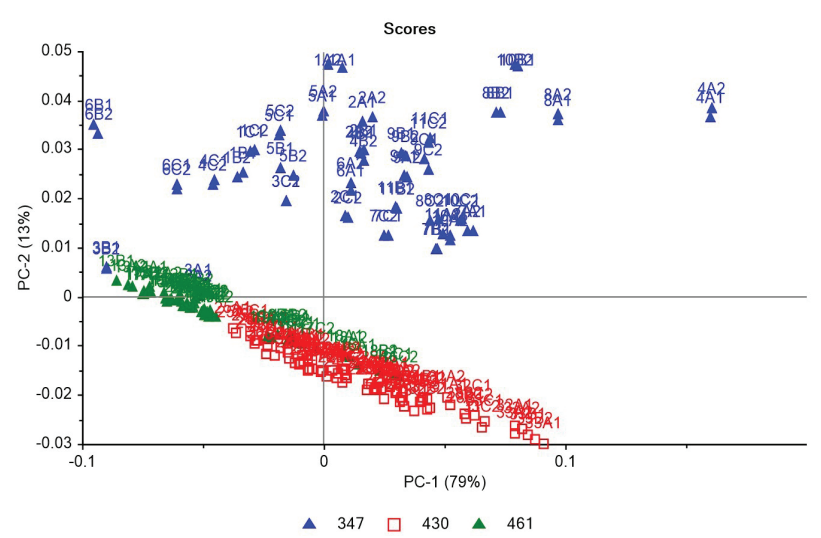

Figure 1. Scores plot resulting from the principal component analysis (PCA) of batches 347 (blue), 430 (red) and 461 (green), using ESI(+)-MS.

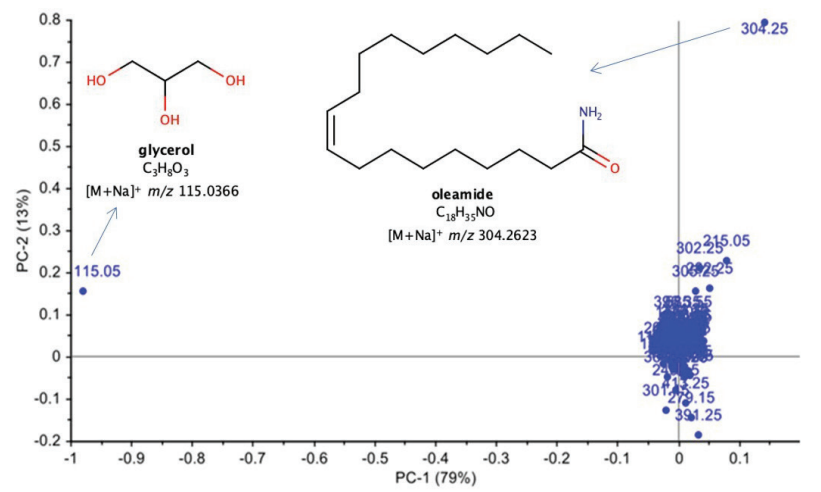

Figure 2. Loadings plot resulting from the principal component analysis (PCA) of batches 347,430 and 461, with structural formula of the putative compounds found in highlights on ESI(+)-MS.

ion $[\mathrm{M}+\mathrm{Na}]^{+} \mathrm{m} / \mathrm{z} 304.2623$ to a nitrogenous compound oleamide $\left(\mathrm{C}_{18} \mathrm{H}_{35} \mathrm{NO}\right)$, which is an amide derived from oleic acid.

Since the glycerol/glycerin ion $\left([\mathrm{M}+\mathrm{Na}]^{+} m / z\right.$ 115.0366) refers to the substrate (feedstock), it was excluded and a new PCA were done in order to identify more compounds (Figures 3 and 4). The variance explained was $71 \%$ combining PC1 and PC2. At the scores plot, two main groups of samples were observed, one in green and red with samples from batches 430 and 461 and another in blue with samples from batch 347 , except samples $3 \mathrm{~A}$ and $3 \mathrm{~B}$ that stayed together with batches 430 and 461 , because these samples showed a very low intensity of the ion $[\mathrm{M}+\mathrm{Na}]^{+} \mathrm{m} / \mathrm{z} 304.2623$.

The heterogeneous group consisting of samples from batch 347 (blue) showed high concentration of the ion $[\mathrm{M}+\mathrm{Na}]^{+} \mathrm{m} / z, 304.2623$ when compared to batches 430 and 461. Other ions stood out in the batch 347 (blue), such as, $m / z$ 215.05, 282.25, 302.25 and 177.05, and their suggested identification was done using the KEGG and METLIN database platforms for searching and comparison with compounds already described in the literature (see Table 1). The PC1 separation was mainly influenced by ion

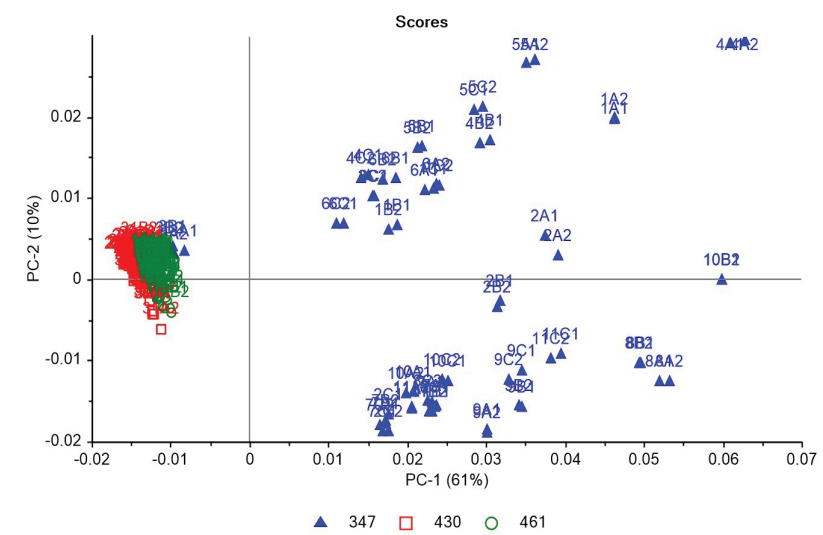

Figure 3. Scores plot resulting from the principal component analysis (PCA) of batches 347 (blue), 430 (red) and 461 (green), ESI(+)-MS, removing the glycerol ion $\left([\mathrm{M}+\mathrm{Na}]^{+} \mathrm{m} / z\right.$ 115.0366).

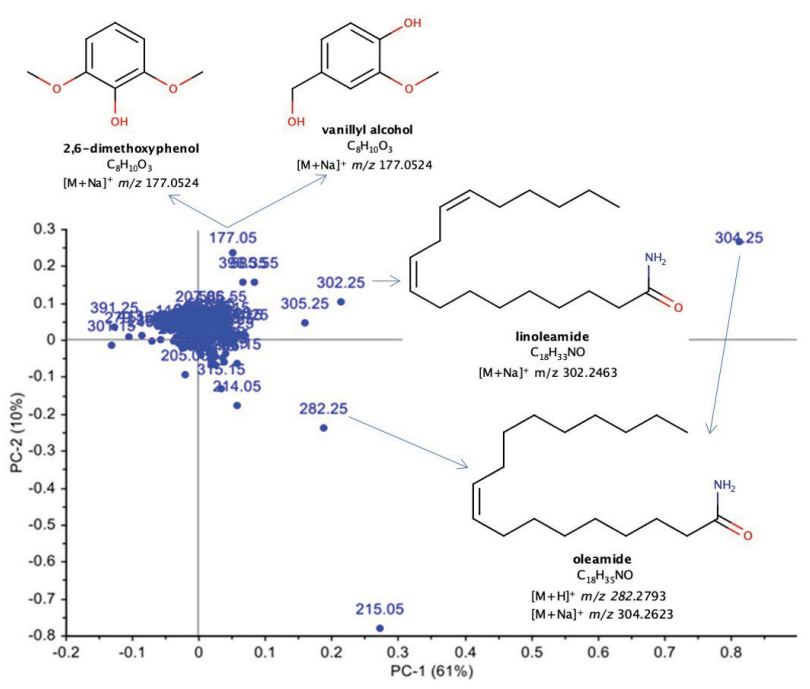

Figure 4. Loadings plot resulting from the principal component analysis (PCA) of batches 347,430 and 461, removing the glycerol ion $\left([\mathrm{M}+\mathrm{Na}]^{+}\right.$ $\mathrm{m} / \mathrm{z}$ 115.0366), with structural formula of some putative compounds found in samples of batch 347 on ESI(+)-MS.

$[\mathrm{M}+\mathrm{Na}]^{+} \mathrm{m} / 2304.2623$ and the PC2 was more influenced by ion $m / z 215.05$ (found mass $[\mathrm{M}+\mathrm{Na}]^{+} \mathrm{m} / z 215.0694$ ), Figure 4. Ion $[\mathrm{M}+\mathrm{Na}]^{+} \mathrm{m} / z 215.0694$ could not be identified because it showed many compound options in the database, so further studies will be necessary to narrow down the possibilities and confirm this compound. Another ion highlight such as $m / z, 282.25$ (found mass $[\mathrm{M}+\mathrm{H}]^{+}$ $\mathrm{m} / \mathrm{z}, 282.2793$ ) was suggested as protonated oleamide. Ion $\mathrm{m} / \mathrm{z} 302.25$ (found mass $[\mathrm{M}+\mathrm{Na}]^{+} \mathrm{m} / \mathrm{z} 302.2463$ ) was suggested to correspond to linoleamide, and finally, ion

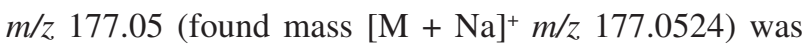
assigned to two putative compounds: 2,6-dimethoxyphenol and vanillyl alcohol.

Bar plots with the intensity of each ion per sample were constructed (Figure 5) to confirm which sample were more promising to produce the compounds mentioned above. Figure 5 a shows the bar plot of oleamide 
Table 1. Suggested compounds to the most relevant ions found in the principal component analysis (PCA), obtained from KEGG and METLIN databases

\begin{tabular}{lccccc}
\hline Found $m / z$ & Calculated $m / z$ & Error / ppm & Molecular formula & Adduct & Suggested compound \\
\hline 177.0524 & 177.0522 & 1.1 & $\mathrm{C}_{8} \mathrm{H}_{10} \mathrm{O}_{3}$ & {$[\mathrm{M}+\mathrm{Na}]^{+}$} & 2,6-dimethoxyphenol or vanillyl alcohol \\
302.2463 & 302.2455 & 2.7 & $\mathrm{C}_{18} \mathrm{H}_{33} \mathrm{NO}$ & {$[\mathrm{M}+\mathrm{Na}]^{+}$} & linoleamide \\
282.2793 & 282.2794 & 3.5 & $\mathrm{C}_{18} \mathrm{H}_{35} \mathrm{NO}$ & {$[\mathrm{M}+\mathrm{H}]^{+}$} & oleamide \\
304.2623 & 304.2611 & 3.9 & $\mathrm{C}_{18} \mathrm{H}_{35} \mathrm{NO}$ & {$[\mathrm{M}+\mathrm{Na}]^{+}$} & citric acid $^{\mathrm{a}}$ \\
191.0203 & 191.0197 & 3.1 & $\mathrm{C}_{6} \mathrm{H}_{7} \mathrm{O}_{7}$ & {$[\mathrm{M}-\mathrm{H}]^{-}$} & hexadecanoic acid $^{-}$ \\
255.2334 & 255.2330 & 1.6 & $\mathrm{C}_{16} \mathrm{H}_{32} \mathrm{O}_{2}$ & {$[\mathrm{M}-\mathrm{H}]^{-}$} & \\
\hline
\end{tabular}

${ }^{a}$ Citric acid identity was confirmed by ESI-MS/MS and UHPLC-PDA analysis using commercial standard.

$\left([\mathrm{M}+\mathrm{Na}]^{+} \mathrm{m} / \mathrm{z}\right.$ 304.2623), which clearly confirms that all samples of batch 347 have it, with exception of samples $3 \mathrm{~A}$ and $3 \mathrm{~B}$, that have low intensity production of this ion. The most promising samples are $4 \mathrm{~A}, 8 \mathrm{~A}$, $8 \mathrm{~B}$ and $10 \mathrm{~B}$ that have most intense compound detected. Although in lower intensity when compared to sodiated oleamide, protonated oleamide was also found $\left([\mathrm{M}+\mathrm{H}]^{+}\right.$ $m / z$ 282.2793) in almost the same promising samples: $8 \mathrm{~A}$,
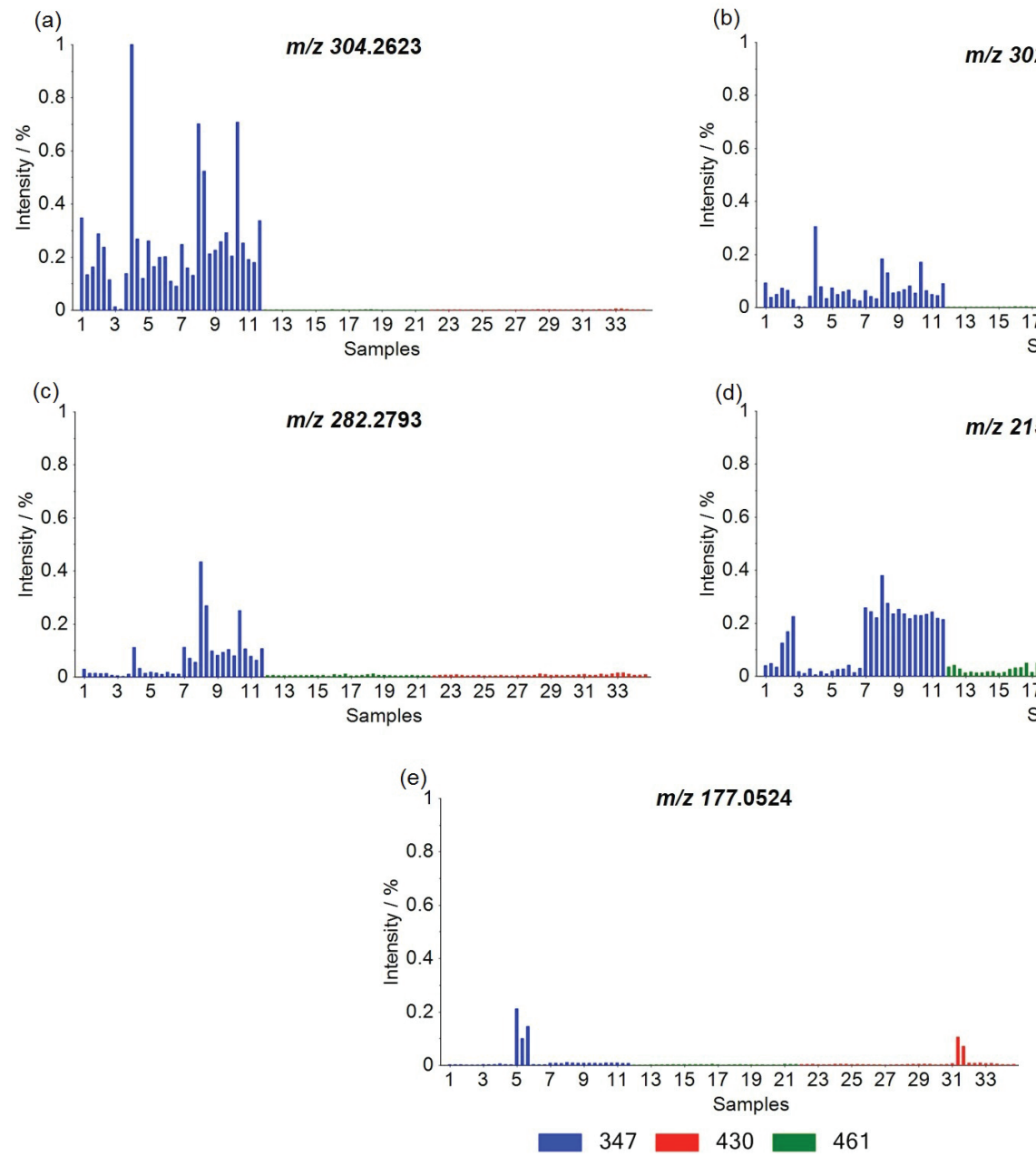

Figure 5. Bar plots with the relative intensity of the ions (a) $[\mathrm{M}+\mathrm{Na}]^{+} \mathrm{m} / z$ 304.2623; (b) $[\mathrm{M}+\mathrm{Na}]^{+} \mathrm{m} / \mathrm{z} 302.2463$; (c) $[\mathrm{M}+\mathrm{H}]^{+} \mathrm{m} / z$ 282.2793; (d) $[\mathrm{M}+\mathrm{Na}]^{+}$ $\mathrm{m} / \mathrm{z}$ 215.0694; (e) $[\mathrm{M}+\mathrm{Na}]^{+} \mathrm{m} / z .177 .0524$ in samples of the batches 347 (blue), 430 (red) and 461 (green).
8B and 10B (Figure 5c). Samples 4A, 8A, 8B and 10B were the most promising to the linoleamide $\left([\mathrm{M}+\mathrm{Na}]^{+}\right.$ $m / z$ 302.2463) production (Figure 5b). The ion $[\mathrm{M}+\mathrm{Na}]^{+}$ $\mathrm{m} / \mathrm{z}$ 215.0694, it was detected in all three batches, however, samples 2B, 2C, 7A-11C from batch 347 presented the higher intensities (Figure 5d). Finally, the production of the 2,6-dimethoxyphenol or vanillyl alcohol $\left([\mathrm{M}+\mathrm{Na}]^{+}\right.$ $m / z, 177.0524)$ were highlighted in samples from batches
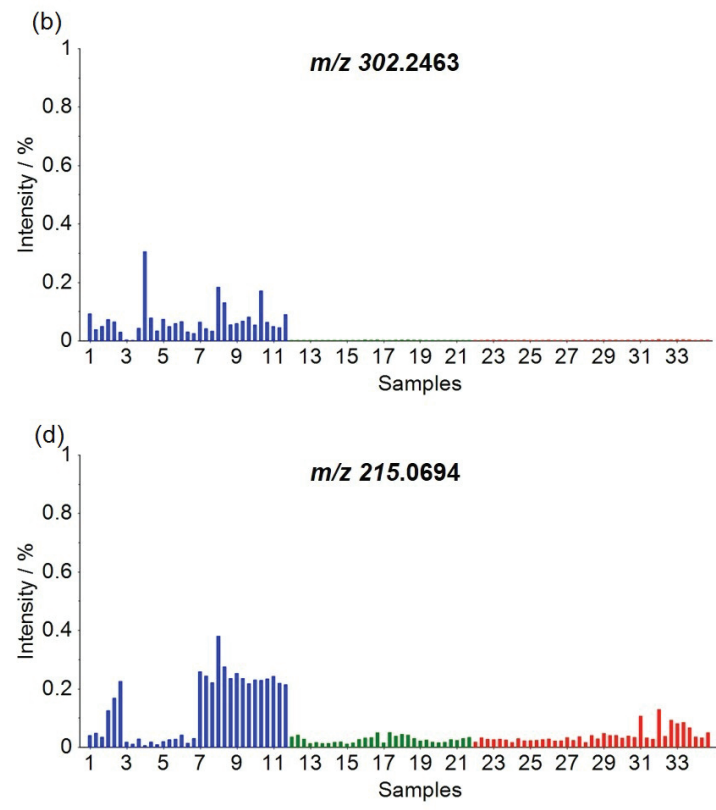
347 (5A, 5B, 5C) and 430 (31B and 31C) (Figure 5e). All highlighted ions in samples batches, analyzed in positive mode, are not present in the fungi culture medium (blank samples), see SI section (Figure S2a). It is worth mentioning that the ions present in the blank samples were not resulted from bioconversion by the filamentous fungi.

The same analyses performed on ESI(+)-MS were repeated on ESI(-)-MS. So, PCA analysis of data were also performed and results explained a variance of $76 \%$ $(\mathrm{PC} 1+\mathrm{PC} 2)$. Figure 6 shows scores plot with different grouping when compared with ESI(+)-MS. Sample 2 from batch 347 (blue) stood out from the others, resulting in a grouping in the lower right quadrant of the scores plot, caused by the influence of ion $\mathrm{m} / \mathrm{z}, 191.05$ (found mass $[\mathrm{M}-\mathrm{H}]^{-} \mathrm{m} / \mathrm{z}$ 191.0203), showed in the Figure 7. This ion was suggested by database platforms as citric acid.

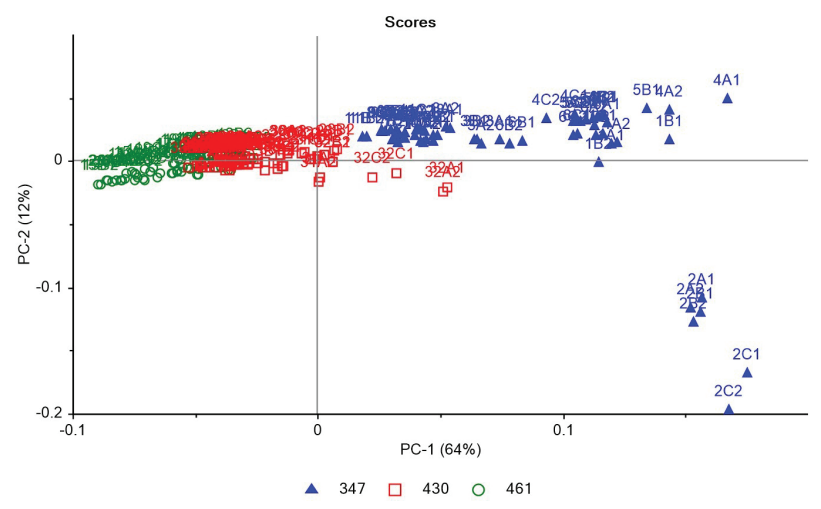

Figure 6. Scores plot resulting from the principal component analysis (PCA) of batches 347 (blue), 430 (red) and 461 (green), in the ESI(-)-MS analysis.

Other ions had stood out in loadings plot as $\mathrm{m} / \mathrm{z} 95.05$, 96.95, 110.95, 210.95 and 255.25 (Figure 7). When we did culture medium MS analysis in negative mode ESI(-)-MS, we found some of these ions as $\mathrm{m} / \mathrm{z}$ 96.9598, 110.9755 and 210.9889, so these compounds were not resulted from bioconversion by filamentous fungi, but they were from substrate (feedstock), see Figure S2b. Unfortunately, by

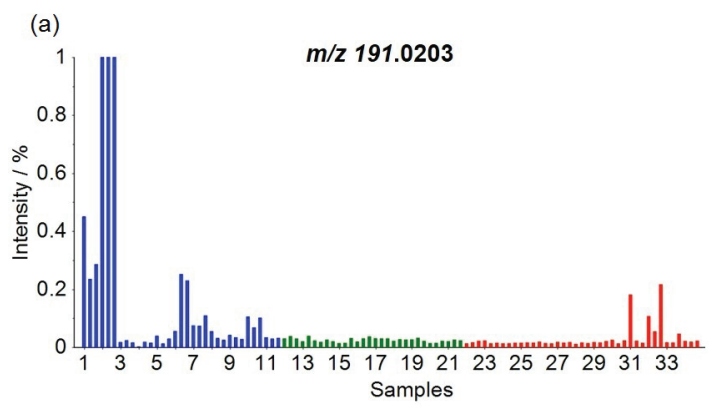

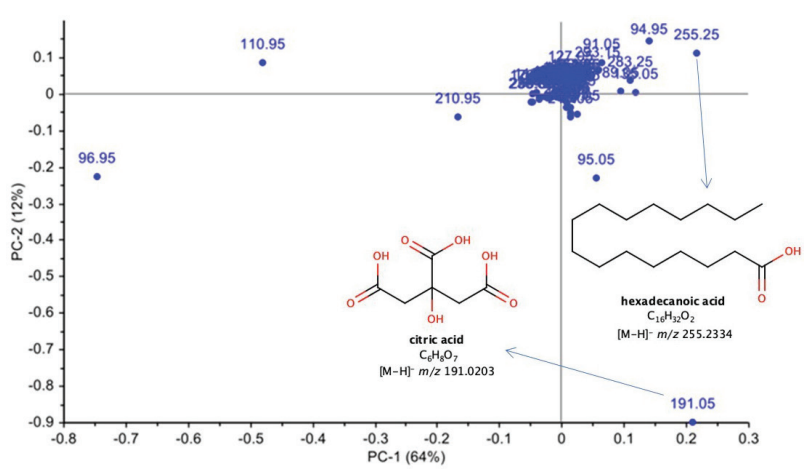

Figure 7. Loadings plot resulting from the principal component analysis (PCA) of batches 347, 430 and 461, in the ESI(-)-MS analysis.

compounds databases search, we could not identify ion $\mathrm{m} / \mathrm{z}$ 95.05, however, we could suggest ion identification $\mathrm{m} / \mathrm{z} 255.25$ (found mass $[\mathrm{M}-\mathrm{H}]^{-} \mathrm{m} / \mathrm{z} 255.2334$ ) as another acid compound, named hexadecanoic acid. Therefore, according to ESI(-)-MS, the most promising produced compounds were citric acid and hexadecanoic acid.

Relative intensity of each highlight compounds in the ESI(-)-MS analysis can be seen in Figure 8. Sample 2 (2A, 2B and 2C) had high intensity to ion $[\mathrm{M}-\mathrm{H}]^{-} \mathrm{m} / \mathrm{z}$ 191.0203, corresponding to citric acid, and it was detected in all three batches with different intensities (Figure 8a). Regarding the hexadecanoic acid, although it was detected in the three batches, it was observed in greater intensity just in 347 , with spotlight on samples $1 \mathrm{~A}, 1 \mathrm{~B}, 1 \mathrm{C}, 3 \mathrm{C}-5 \mathrm{~B}$ and $6 \mathrm{~A}$.

To confirm that the compound previously detected by DIMS in the ESI(-)-MS analysis was citric acid, we did MS/MS experiments (Figure S3, SI section) to compare the fragmentation pattern with METLIN database. Additionally, we performed UHPLC-PDA analysis to make sure that the highlight ion was citric acid with comparison using commercial standard (Figures S4a and S4b). Sample 2C co-injection with comercial standard of citric acid presented a peak at the same retention time of citric acid standard, $4.4 \mathrm{~min}$, which is the same retention time presented in the fortified sample. The relative

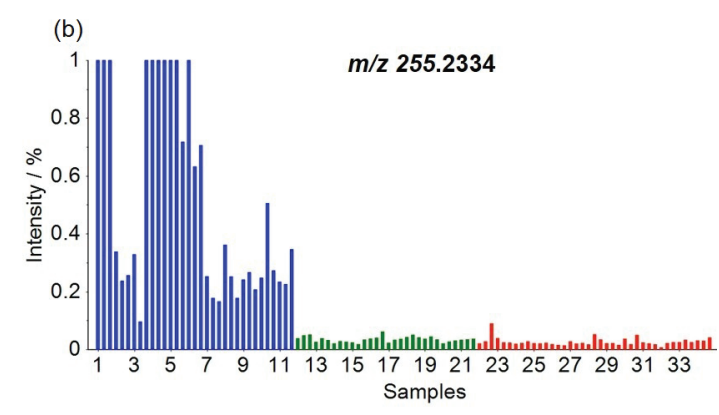

$347-430 \square 461$

Figure 8. Bar plots with the relative intensity of citric acid $\left([\mathrm{M}-\mathrm{H}]^{-} \mathrm{m} / z\right.$ 191.0203) and hexadecanoic acid $\left([\mathrm{M}-\mathrm{H}]^{-} \mathrm{m} / \mathrm{z} 255.2334\right)$ in samples of the batches 347 (blue), 430 (red) and 461 (green), in the ESI(-)-MS analysis. 
quantification of this compound by peak area value is presented in Table S2 (SI section). All these results are presented in the Supplementary Information (Table S2 and Figures S3 and S4).

Finally, the main compounds found in this work are presented in Table 1, with suggested compound, adduct, molecular formula, ppm error, found and calculated mass. Mass spectra of these compounds are presented in Supplementary Information from Figure S5 to Figure S10.

\section{Conclusions}

DIMS is a high throughput sensitive and selective technique to the screening of compounds and could be successfully applied to bioprospecting chemicals produced from bioprocess. The time of analysis per sample is much less compared to LC-MS technique, since it does not require the use of column, therefore, providing a fast screening, with higher reproducibility (no instrument drift), enabling the analysis of more samples in a shorter time, which is an excellent tool for "first-pass" fingerprinting analysis of complex biological samples.

Multivariate data analysis (PCA) applied to DIMS data were a suitable tool to differentiate the production of compounds by the filamentous fungi evaluated. Moreover, the use of DIMS have proved to be very pragmatic, in order to detect the most promising microorganisms capable to bioconvert glycerin into value added compounds such as amide derivatives, phenolic and acid compounds.

From 34 filamentous fungi from three batches (347, 430 and 461) analyzed in this work, fungi from batch 347 stood out. Analysis of ESI(+)-MS indicates that microorganisms used to generate the samples $4 \mathrm{~A}, 8 \mathrm{~A}$, $8 \mathrm{~B}$ and $10 \mathrm{~B}$ were the most promising to the production of amide compounds. On the other hand, microorganisms used to obtain the samples $2 \mathrm{~B}, 2 \mathrm{C}, 5 \mathrm{~A}, 5 \mathrm{~B}, 5 \mathrm{C}$, $7 \mathrm{~A}-11 \mathrm{C}, 31 \mathrm{~B}$ and $32 \mathrm{C}$ are promising to the production of phenolic compounds. Analysis in the ESI(-)-MS indicated that samples $2 \mathrm{~A}, 2 \mathrm{~B}$ and $2 \mathrm{C}$ were the most promising to production of citric acid. As the expected chemicals portfolio produced from the bioconversion of glycerin were organic acids and polyols, only citric acid compound identity was further confirmed by MS/MS and UHPLC-PDA analyses. Next step of this work should be to corroborate these data using quantitative methods, and hereafter the optimization of the bioprocess using the microorganisms which produce the chemical compounds with higher yields.

The analytical platform presented in this work was practical, fast and robust, and it was successfully applied to perform screening of several samples in a short-time analysis (around 5 min per sample), and to suggest a wide range of compounds, not being necessary the use of standards. The platform is versatile and widely used by our group to bioprospecting potential microorganisms able to bioconvert low value residue into high value chemicals, using different substrates, bioprocesses or microorganisms.

\section{Supplementary Information}

Supplementary information (PCA validation, UHPLCPDA experiments and HRMS spectra) is available free of charge at http://jbcs.sbq.org.br as PDF file.

\section{Acknowledgments}

The authors would like to thank the Brazilian Agricultural Research Corporation (EMBRAPA), the Federal Foundation for the Brazilian Research and Development (FINEP), Coordination for the Improvement of Higher Education Personnel (CAPES), National Council for Scientific and Technological Development (CNPq) and Federal University of Goiás (UFG) for the institutional and financial support. The grants funding this work were: 404854/2013-3 (Bioglic Project, CNPq); 183-15/2014 (CAPES-EMBRAPA Project); 03.14.04.004.00.00 (ChemSearch Project, EMBRAPA/SEG) and 01.13.0315.02 (DendePalm Project, FINEP).

\section{References}

1. Octave, S.; Thomas, D.; Biochimie 2009, 91, 659.

2. Maity, S. K.; Renewable Sustainable Energy Rev. 2015, 43, 1427.

3. Schultz, E. L.; de Souza, D. T.; Damaso, M. C. T.; Chem. Biol. Technol. Agric. 2014, 1, 7.

4. Mota, C. J. A.; da Silva, C. X. A.; Gonçalves, V. L. C.; Quim. Nova 2009, 32, 639.

5. Padilha, A. C. M.; Gollo, S. S.; da Silva, M. N.; Estudos na Cadeia Produtiva do Biodiesel, $1^{\text {a }}$ ed.; Unipampa: Jaguarão, Brasil, 2012.

6. Conselho Nacional de Política Energética (CNPE), Resolução No. 16, de 29/10/2018, DOU 08/11/2018, No. 215, Seção 1, p. 2, 2018.

7. Rahman, M. S.; Xu, C. C.; Ma, K.; Guo, H.; Qin, W.; Renewable Energy 2017, 114, 1272.

8. Chen, Z.; Liu, D.; Biotechnol. Biofuels 2016, 9, 205.

9. Willke, T.; Vorlop, K.; Eur. J. Lipid Sci. Technol. 2008, 110, 831.

10. Abdelnur, P. V.; Caldana, C.; Martins, M. C. M.; Chem. Biol. Technol. Agric. 2014, 1, 22. 
11. Martien, J. I.; Amador-Noguez, D.; Anal. Biotechnol. 2017, 43, 118.

12. Rao, L. V.; Goli, J. K.; Gentela, J.; Koti, S.; Bioresour. Technol. 2016, 213, 299.

13. Monedero, V.; Pérez-Martínez, G.; Yebra, M. J.; Appl. Microbiol. Biotechnol. 2010, 86, 1003.

14. Ahn, J. H.; Jang, Y.-S.; Lee, S. Y.; Curr. Opin. Biotechnol. 2016, $42,54$.

15. Ikeuchi, T.; Azuma, M.; Kato, J.; Ooshima, H.; Biomass Bioenergy 1999, 16, 333.

16. Lin, S.-J.; Wen, C.-Y.; Liau, J.-C.; Chu, W.-S.; Process Biochem. 2001, 36, 1249 .

17. Almeida, J. R. M.; Fávaro, L. C. L.; Quirino, B. F.; Biotechnol. Biofuels 2012, 5, 48.

18. Liu, X.; Ai, N.; Zhang, H.; Lu, M.; Ji, D.; Yu, F.; Ji, J.; Carbohydr. Res. 2012, 353, 111.

19. Souto, A. L.; de Oliveira, V. M.; da Silva, V. C.; Correia, M. V.; da Silva, W. P.; Trindade, M. A. G.; Rodrigues, C. M. In Analytical Techniques and Methods for Biomass, $1^{\text {st }}$ ed.; Vaz Jr., S., ed.; Springer International Publishing: Cham, 2016, p. 197-234.

20. Ricci-Silva, M. E.; Vaz, B. G.; Vasconcelos, G. A.; Romão, W.; Aricetti, J. A.; Caldana, C.; Abdelnur, P. V. In Analytical Techniques and Methods for Biomass, $1^{\text {st }}$ ed.; Vaz Jr., S., ed.; Springer International Publishing: Cham, 2016, p. 115-141.

21. Degtyarenko, K.; de Matos, P.; Ennis, M.; Hastings, J.; Zbinden, M.; McNaught, A.; Alcántara, R.; Darsow, M.; Guedj, M.; Ashburner, M.; Nucleic Acids Res. 2008, 36, D344.

22. Ogata, H.; Goto, S.; Sato, K.; Fujibuchi, W.; Bono, H.; Kanehisa, M.; Nucleic Acids Res. 1999, 27, 29.

23. Guijas, C.; Montenegro-Burke, J. R.; Domingo-Almenara, X.; Palermo, A.; Warth, B.; Hermann, G.; Koellensperger, G.; Huan, T.; Uritboonthai, W.; Aisporna, A. E.; Wolan, D. W.; Spilker, M. E.; Benton, H. P.; Siuzdak, G.; Anal. Chem. 2018, 90, 3156.
24. Nanita, S. C.; Kaldon, L. G.; Anal. Bioanal. Chem. 2016, 408, 23.

25. Michel, D.; Gaunt, M. C.; Arnason, T.; El-Aneed, A.; J. Pharm. Biomed. Anal. 2015, 107, 229.

26. Beckmann, M.; Parker, D.; Enot, D. P.; Duval, E.; Draper, J.; Nat. Protoc. 2008, 3, 486.

27. Draper, J.; Lloyd, A. J.; Goodacre, R.; Beckmann, M.; Metabolomics 2013, 9, 4.

28. Catchpole, G. S.; Beckmann, M.; Enot, D. P.; Mondhe, M.; Zywicki, B.; Taylor, J.; Hardy, N.; Smith, A.; King, R. D.; Kell, D. B.; Fiehn, O.; Draper, J.; Proc. Natl. Acad. Sci. U. S. A. 2005, 102, 14458.

29. Enot, D. P.; Lin, W.; Beckmann, M.; Parker, D.; Overy, D. P.; Draper, J.; Nat. Protoc. 2008, 3, 446.

30. Fontes, P. R.; Ribeiro, J. A. A.; Costa, P. P. K. G.; Damaso, M. C. T.; Gonzalez, W. A.; dos Santos, C. M. C.; Abdelnur, P. V.; Rodrigues, C. M.; Anal. Methods 2016, 8, 2048.

31. Campos, C. G.; Veras, H. C. T.; Ribeiro, J. A. A.; Costa, P. P. K. G.; Araújo, K. P.; Rodrigues, C. M.; de Almeida, J. R. M.; Abdelnur, P. V.; J. Am. Soc. Mass Spectrom. 2017, 28, 2646.

32. Wold, S.; Esbensen, K.; Geladi, P.; Chemom. Intell. Lab. Syst. 1987, 2, 37.

33. Capriles, C. H.; Mata, S.; Middelveen, M.; Mycopathologia 1989, 106, 73.

34. Ribani, M.; Bottoli, C. B. G.; Collins, C. H.; Jardim, I. C. S. F.; Melo, L. F. C.; Quim. Nova 2004, 27, 771.

35. Unscrambler $X$, version 10; CAMO Analytics AS, Norway, 2016.

Submitted: April 4, 2019

Published online: September 2, 2019 